\title{
The Profile of Communicative Appropriateness: A Clinical Tool for the Assessment of Pragmatics
}

\author{
Claire Penn Ph.D (Witwatersrand) \\ Department of Speech Pathology \& Audiology, \\ University of the Witwatersrand, Johannesburg
}

\section{ABSTRACT}

The Profile of Communicative Appropriateness - a newly developed profile for the characterisation of pragmatics is described. The theoretical background to this profile is covered as well as its main components. Its application to a group of eighteen aphasic patients is outlined, results suggesting that patient groupings on the profile could be predicted in terms of severity but not in terms of type of aphasia. Explanations for this finding are discussed and the potential utility of this profile is suggested.

\section{OPSOMMING}

Die Profile of Communicative Appropriateness - 'n nuttontwikkelde profiel vir die karakterisering van pragmatiek word beskryf. Die teoretiese rasionaal hieragter en die hoofkomponente van die profiel word behandel. Die toepassing hiervan op ' $n$ groep van agtien afatiese pasiente word omskryf. Resultate dui daarop dat die pasientgroeperings aanduidend kan wees van die erns van afasie maar nie van die tipe afasie nie. Verduidelikings hiervoor en die potensiële bruikbaarheid van die profiel word bespreek.

The clinical profile is a method of characterising language which has become increasingly popular in recent years. Essentially " ... a linguistic profile is a principled description of ... those features of a person's ... use of language which will enable him to be identified for a specific purpose." (Crystal, 1982). The format of such a profile is the presentation of a wide range of variables simultaneously so that the clinician is able to see at a glance the communicative assets and deficits of a patient.

(C) SASHA 1985
The main purpose of such a profile according to Crystal (1982) is to provide not only a comprehensive description of a patient's data but also an adequate basis for remedial intervention. It is not a standardized measure; nor is it an exhaustive linguistic description. The profile is, however, a compromise to the clinician faced with the realisation that language disability requires comprehensive and individual description. The amount of information contained on a profile is determined by the behaviours being measured The South African Journal of Communication Disorders, Vol. 32, 1985 
as well as the purpose of the tool. However, it is imperative that the categories are clinically relevant i.e. that they can potentially distinguish patients with differing symptoms.

The language behaviours which can be characterised by profile are numerous. Crystal and his co-workers developed the LARSP profile in 1976 to characterise expressive syntax and have subsequently introduced profiles to describe phonology, prosody and semantics (Crystal, 1982). Prutting has developed a profile (protocol), based on speech act theory designed to characterise pragmatic capabilities (Prutting and Kirchner, 1983).

This paper will describe an alternative pragmatic profile, developed over some years viz. The Profile of Communicative Appropriateness (PCA).

The PCA is a linguistic profile designed to characterize the communicative competence of a clinical subject. It was developed to identify the features of communication evading description by traditional methods. It is concerned primarily with language use beyond the sentence level and is based on a number of theoretical assumptions from the field of pragmatics. Before a consideration of the PCA and its application, this theoretical basis will be examined in further detail.

\section{THEORETICAL BACKGROUND}

The field of pragmatics has been defined as the study of "...the rules governing the use of language in context" (Bates, 1976). According to Prutting (1982) "the context in which communication takes place is highly complex and includes multidimensional aspects of the environment". It takes into account the people present in the interaction, what was said before, the topic of conversation, the task of communication and the time and place of the interaction.

In Figure 1 the main components of the communicative context are isolated viz. participants, codes, channels, setting and content.

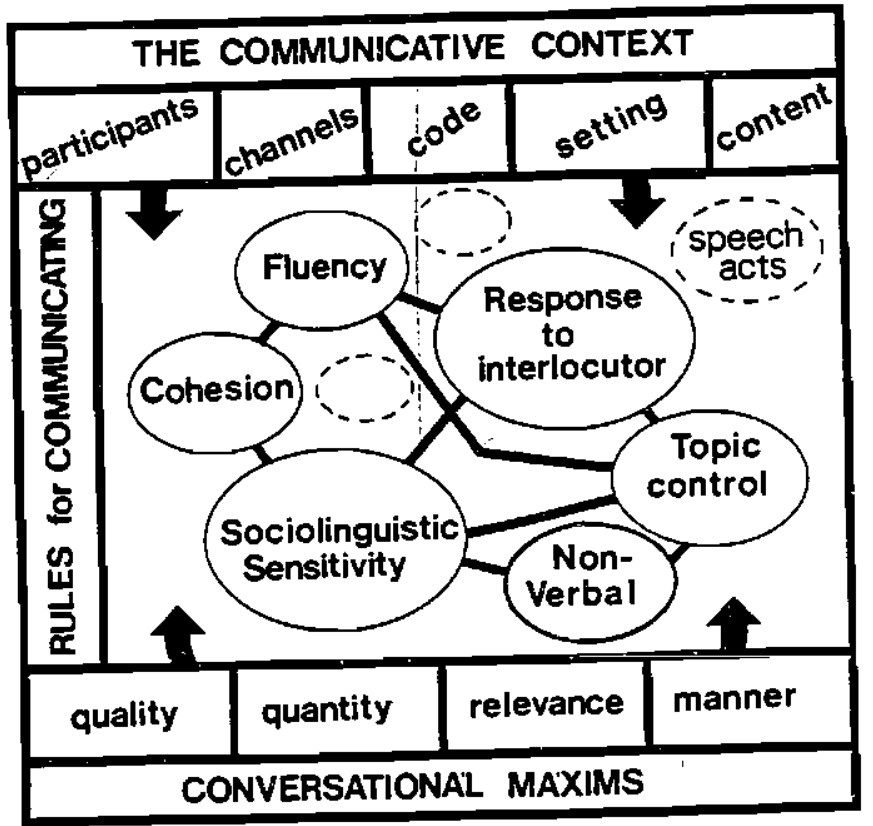

Figure 1 The Realm of Pragmatics

Although in the field of linguistics and in language pathology, there Although in the field of linguistics and in language pathol what Prutting (1983) calls a "paradigm shift" towards the field of pragmatics, the area is a complex one and as yet ill defined. Many linguists have declared a reluctance to incorporate such contextual factors into a model of language, their claim being that such considerations fall outside the realm of linguistics per se. On the other hand, there is ample evidence to suggest that many aspects of communicative competence are amenable to analysis and can be systematically described and related. These aspects have for the most part been dealt with largely independently in the literature and have different frameworks of analysis. Aside from the work of Bates (1976) there is as yet no cohesive theory of pragmatics which attempts to combine the study of language use into a unified whole. At this stage a discussion of pragmatics therefore probably necessitates a consideration of its component parts. Central components selected for discussion here are reflected schematically in Figure 1 - viz. Response to Interlocutor, Topic Control, Cohesion, Fluency, Sociolinguistic Sensitivity and Non-verbal Communication. To separate these particular aspects is a somewhat artificial exercise as there are many areas of overlap. The reasons for considering them separately are governed by their distinction in the literature, their relative independence from a methodological perspective, but most important by their potential practical separation as useful areas for the characterization of pathological language. It is beyond the scope of this paper to present in any depth the scope and theoretical underpinnings to the aspects discussed. This has been described elsewhere (Penn 1983a). Presented here is merely an outline of the main components of Communicative Competence with their respective definitions.

\section{COMPONENTS OF COMMUNICATIVE COMPETENCE}

Probably the most important area of control which the normal speaker-hearer has over his language in real life is his competence with regard to discourse. Most human communication takes place beyond a sentence level i.e. in dialogue or in conversations. Appropriate response to an interlocutor thus involves knowledge of the rules of discourse and an understanding of the speaker's intention with regard to a particular utterance. Coherence is a central feature of discourse i.e. the property that makes a discourse more than a collection of unrelated simple sentences. Two aspects of coherence in discourse may be identified - the first is related to Control of topic or of Semantic Content. Keenan and Schieffelin (1976) define discourse topic as the proposition about which the speaker is either providing or requesting new information. The rules for topic cooperation are very complex including those for topic shifting, shading (expansion) and reintroduction. The notion of cohesion is the second major component of coherence. This refers to the way in which sentences are linked within a discourse. Cohesion may be expressed through the syntax or vocabulary and includes components such as reference, substitution, ellipsis and conjunction, all of which have been discussed at length by workers such as Halliday and Hasan (1976).

Fluency is another aspect of communicative competence which has been examined in considerable detail by both linguists and speech pathologists. It is considered as a sensitive indicator of the potency of the communicative system. Dalton and Hardcastle (1977) point out that there are two possible ways to view fluency. The first emphasizes temporal and sequential aspects of speech and includes factors such as pauses and interruptions. The second meaning of fluency is derived from the context of language usage and includes adherence to the rules of language. Clearly in characterizing communication, we are concemed with both aspects, though speech therapists have traditionally concerned themselves more with temporal and sequential aspects of fluency (Penn, 1983b).

The term Sociolinguistic Sensitivity coined by Bates and Johnston (1977) describes the speaker's awareness and sensitivity to the contextual features of his utterance and his ability to modify his message in terms of this context. The speaker who is sensitive to the 
sociolinguistic features of the situation will take into account the the participants, and will follow the rules for politeness, self-correction and humour for example.

A communicatively competent speaker will also show good control and understanding of non-verbal transmission of messages. Much has been written during recent years on this channel of communication (Behrmann \& Penn, 1984). It includes areas such as kinesics, proxemics and paralanguage. The function of non-verbal communication changes according to context and the patient's specific abilities. Non-verbal communication is in fact an important component of all aspects of communicative competence discussed previously.

Finally on a more esoteric level, there are certain properties of conversation which determine its overall qualitative level of appropriateness. In order to communicate effectively certain ground rules must be followed by the communicative participants. Borrowing from Kant, Grice (1975) has suggested that four maxims apply in
Conversation: quantity, quality, relation and manner and that these are basic to the rules of cooperative discourse.

By way of a summary of the preceding discussion, Figure 1 illustrates the aspects discussed. It demonstrates the primacy of communicative context over the speaker's use of language and the basic influence of the cooperative principles of conversation. It also indicates the separate (but overlapping) areas of communicative competence discussed above.

The PCA reflects an attempt to capture such aspects for the purposes of clinical description and prediction. A clinically viable version of the PCA is presented in Figure 2. The six main areas of communicative competence are presented as well as the specific linguistic behaviours subsumed under each scale. The PCA evolved from a study designed to investigate the expressive output of a group of adult aphasic patients. It is not the intention of this paper to describe the detailed outcome of this study. What seems important is a consideration of how the PCA evolved and its utility in describing and separating out aphasic subjects.

\begin{tabular}{|c|c|c|c|c|c|c|c|c|}
\hline \multicolumn{3}{|l|}{ Name } & \multicolumn{6}{|c|}{ Features of sampling } \\
\hline \multicolumn{3}{|l|}{ Date } & \multicolumn{6}{|c|}{ Unit of analysis } \\
\hline \multicolumn{9}{|c|}{ Person eliciting sample } \\
\hline & & s & s & 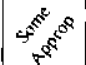 & बئ & ss & $0^{5}$ & CONTENTS \\
\hline \multirow{6}{*}{ 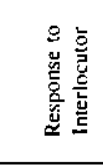 } & Request & & & & & & & \\
\hline & Reply & & & & & & & \\
\hline & \begin{tabular}{|l|} 
Clarification request \\
\end{tabular} & & & & & & & \\
\hline & \begin{tabular}{|l|} 
Acknowledgement \\
\end{tabular} & & & & & & & \\
\hline & Teaching probe & & & & & & & \\
\hline & Others & & & & & & & \\
\hline \multirow{7}{*}{ 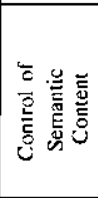 } & Topic iniliation & & & & & & & \\
\hline & \begin{tabular}{|l|} 
Topic adherence \\
\end{tabular} & & & & & & & \\
\hline & \begin{tabular}{|l|} 
Topic shift \\
\end{tabular} & & & & & & & \\
\hline & \begin{tabular}{|l} 
Lexical choice \\
\end{tabular} & & & & & & & \\
\hline & \begin{tabular}{|l|} 
Idea completion \\
\end{tabular} & & & & & & & \\
\hline & Idea sequencing & & & & & & & \\
\hline & Others & & & & & & & \\
\hline \multirow{8}{*}{$\begin{array}{l}\overline{0} \\
\text { 总 } \\
\frac{0}{0}\end{array}$} & Elipsis & & & & & & & \\
\hline & \begin{tabular}{|l|} 
Tense Use \\
\end{tabular} & & & & & & & \\
\hline & \begin{tabular}{|l|} 
Reference \\
\end{tabular} & & & & & & & \\
\hline & \begin{tabular}{|l|l} 
Lexical Substitute forms \\
\end{tabular} & & & & & & & \\
\hline & \begin{tabular}{|l|} 
Relative Clauses \\
\end{tabular} & & & & & & & \\
\hline & Prenominal Adjectives & & & & & & & \\
\hline & \begin{tabular}{|l|} 
Conjunctions \\
\end{tabular} & & & & & & & \\
\hline & Others & & & & & & & \\
\hline \multirow{7}{*}{$\begin{array}{l}\overrightarrow{\overrightarrow{\mathrm{L}}} \\
\frac{\mathrm{z}}{\bar{L}}\end{array}$} & Interjections & & & & & & & \\
\hline & Repetitions & & & & & & & \\
\hline & Incomplete phrases & & & & & & & \\
\hline & \begin{tabular}{|l|} 
False starts \\
\end{tabular} & & & & & & & \\
\hline & Pauses & & & & & & & \\
\hline & Word-finding difficulties & & & & & & & \\
\hline & Others & & & & & & & \\
\hline \multirow{10}{*}{ 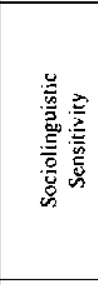 } & Polite forms & & & & & & & \\
\hline & \begin{tabular}{|l|} 
Reference to interlocutor \\
\end{tabular} & & & & & & & \\
\hline & \begin{tabular}{|l|l} 
Placcholders, fillers, stereotypes \\
\end{tabular} & & & & & & & \\
\hline & \begin{tabular}{|l|} 
Acknowledgements \\
\end{tabular} & & & & & & & \\
\hline & \begin{tabular}{|l} 
Self correction \\
\end{tabular} & & & & & & & \\
\hline & Camment clauses & & & & & & & \\
\hline & \begin{tabular}{|l|} 
Sarcasm/humour \\
\end{tabular} & & & & & & & \\
\hline & Control of direct speech & & & & & & & \\
\hline & Indirect speech acts & & & & & & & \\
\hline & Others & & & & & & & \\
\hline \multirow{12}{*}{ 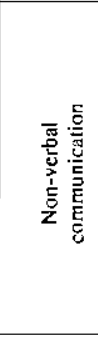 } & Vocal aspects: Intensity & & & & & & & \\
\hline & Pitch & & & & & & & \\
\hline & Rate & & & & & & & \\
\hline & Intonation & & & & & & & \\
\hline & \begin{tabular}{|c|} 
Quality \\
\end{tabular} & & & & & & & \\
\hline & Non-verbal aspects: Facial expression & & & & & & & \\
\hline & \begin{tabular}{|c|} 
Head movement \\
\end{tabular} & & & & & & & \\
\hline & Body posture & & & & & & & \\
\hline & Breathing & & & & & & & \\
\hline & Social distance & & & & & & & \\
\hline & Gesture and pantomime & & & & & & & \\
\hline & Others & & & & & & & \\
\hline & TOTAL & & & & & & & \\
\hline
\end{tabular}

Figure 2 Profile of communicative appropriateness 


\section{THE PCA AND APHASIA}

The PCA evolved in a two-part study conducted over five years. In the first part (part A) the interactive language samples from a group of six aphasics were analysed syntactically using the LARSP profile (Crystal et al, 1976). This syntactic analysis was found not to identify the main communicative features clinically differentiating the subjects. Among such features were factors relating to manner of production, control of content and control over rules of discourse. This led to the derivation of a taxonomy of behaviours designed to represent these aspects. As an audiotaped data base was the basis for analysis, non-verbal communication could not be considered in Study A. In Study B which employed videotaped analysis of the interactive language samples of fourteen subjects, a non-verbal scale was included. The PCA thus measures three broad areas of communicative competence - Control of discourse (measured by Scales A. B and C), Fluency (Scale D) and more global aspects of interactive communication (Scales $\mathbf{E}$ and $\mathbf{F}$ ).

A major concept underlying the PCA is the notion of appropriateness. The language behaviour of an individual may only be judged as being appropriate within the context of a communicative event. The term "appropriate" implies a societal framework of judgement based on the performance of the individual in a social context, rather than on his ability on an "all or none" measure of language on a traditional test.

In the writer's opinion, the perceived impact of an aphasic patient's difficulty can not be evaluated in terms of a score or a quantitative measure, but in terms of qualitative appropriateness.

The issue of how to characterize appropriateness was considered in the present study which used, like Holland (1982) and Prutting and Kirchner (1983), a dichotomy rating of Appropriate/Inappropriate in Study A. In Study B a five-point rating scale was used.

In Study A, the task of the judges (six qualified and specially trained speech pathologists) was to rate each conversational turn in terms of its appropriateness for each aspect of the PCA. A conversational turn was defined as one Therapist-Patient interaction. Difficulties were experienced in analysing the data using statistical procedures for a number of reasons. Firstly, the nature of the judgement proved too precise for the nature of the data under evaluation. Secondly, the large number of judges, while providing valuable insight into the clinical utility of the tool, provided difficulties in the calculation of inter-rater agreement. As a result, in Study B, a five-point rating scale was employed, illustrated in Figure 2. Two trained judges were required to rate the data of the subjects using the five point scale to evaluate each one minute chunk of language data (designated the Conversational Unit) in the sample of each of the subjects. Inter-rater agreement (measured by means of Cohen's weighted Kappa coefficient (Cohen, 1968) reached acceptable levels for each of the six scales. Additional measures for each of the subjects included the administration of the Boston Diagnostic Aphasia Examination (BDAE) (Goodglass \& Kaplan 1972) Holland's CADL (1980), and Sarno's Functional Communication Profile (1975).

The approach to data analysis was essentially taxonomic making use of a technique known as hierarchical cluster analysis. This allows for the clustering of subjects on a particular measure on the basis of their similarity. The outcome of the cluster analysis can be portrayed schematically by means of cluster fields. In Figure $3(a-f)$ the outcome of the cluster analysis on the separate scales of

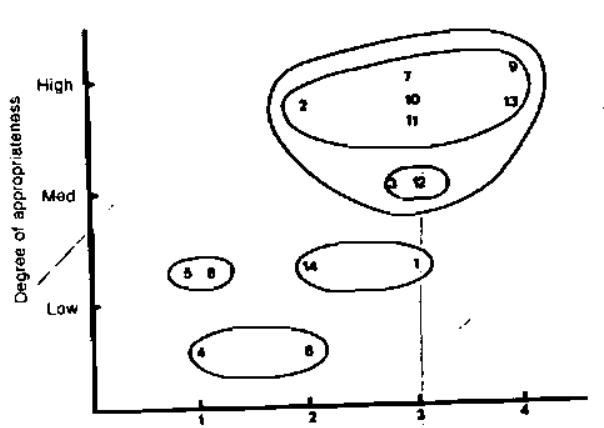

(a)

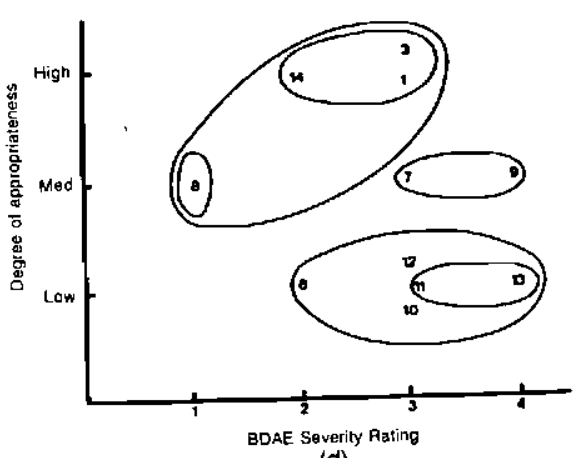

(d)

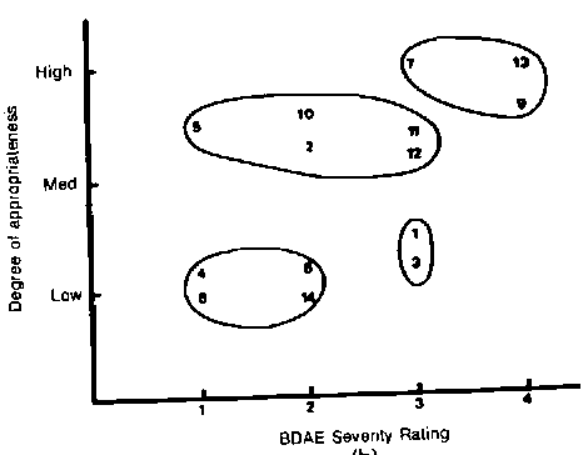

(b)

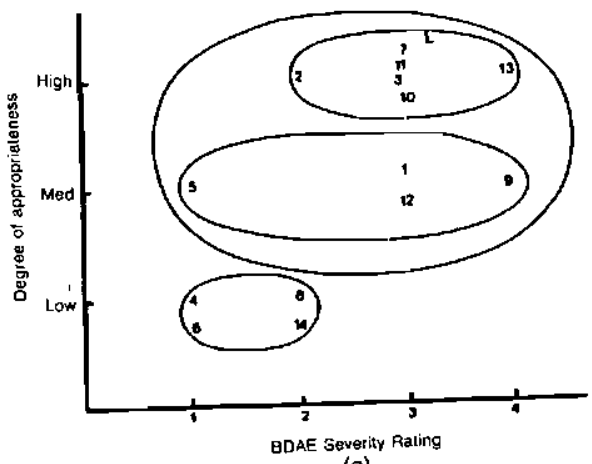

(e)

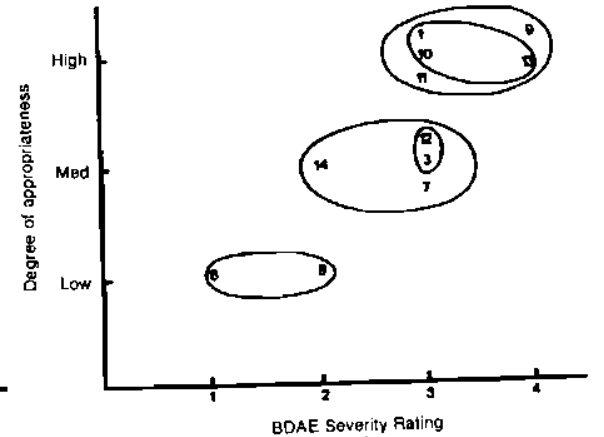

(c)

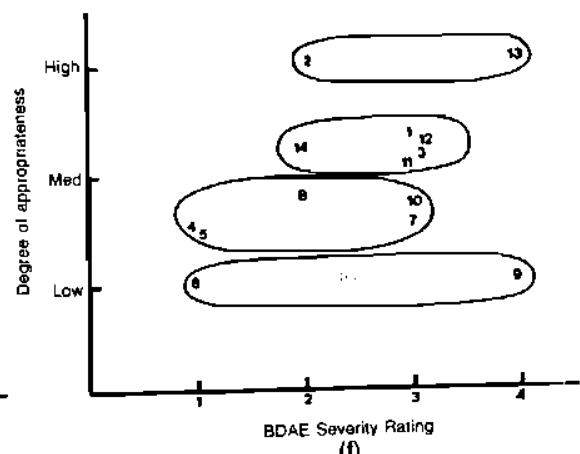

(f)

Figure 3(a-f) Clustering of the subjects on Scales A-F of the PCA in relation to Appropriateness and severity ratings (Study B)

Die Suid-Afrikaanse Tydskrif vir Kommunikasieafwykings, Vol. 32, 1985 
the PCA in Study B is demonstrated as a function of the subjects' severity ratings on the BDAE. These reveal that the subjects clustered into several distinct groups on the basis of appropriateness - the size and the composition of the groups varying according to the scale.

On the whole, results suggested a better retained competence for scales A, B, E and F than for Scales C and D. When results for all scales combined are viewed (Figure 4) two broad subject splits can be identified - The appropriate group (consisting of eight subjects) and the inappropriate group (containing six subjects). These splits correlated broadly with severity (as measured on the BDAE) and with performance on other measures of communication (see Figure 5) but not with the subjects' syntactic capacities nor with type of aphasia.

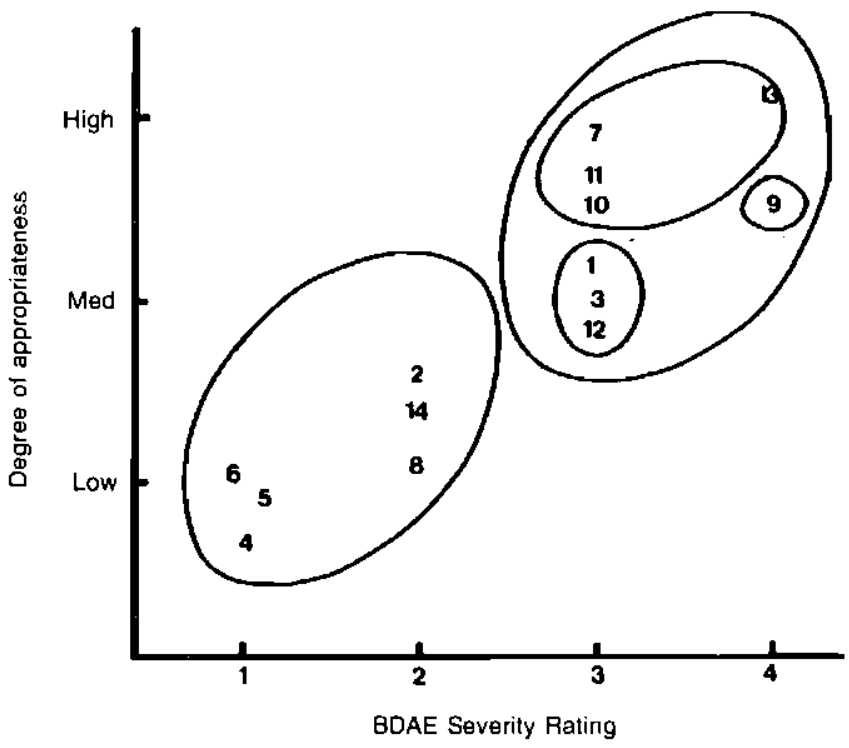

Figure 4 Clustering of the subjects on all Scales of PCA in relation to Appropriateness and severity ratings (Study B)

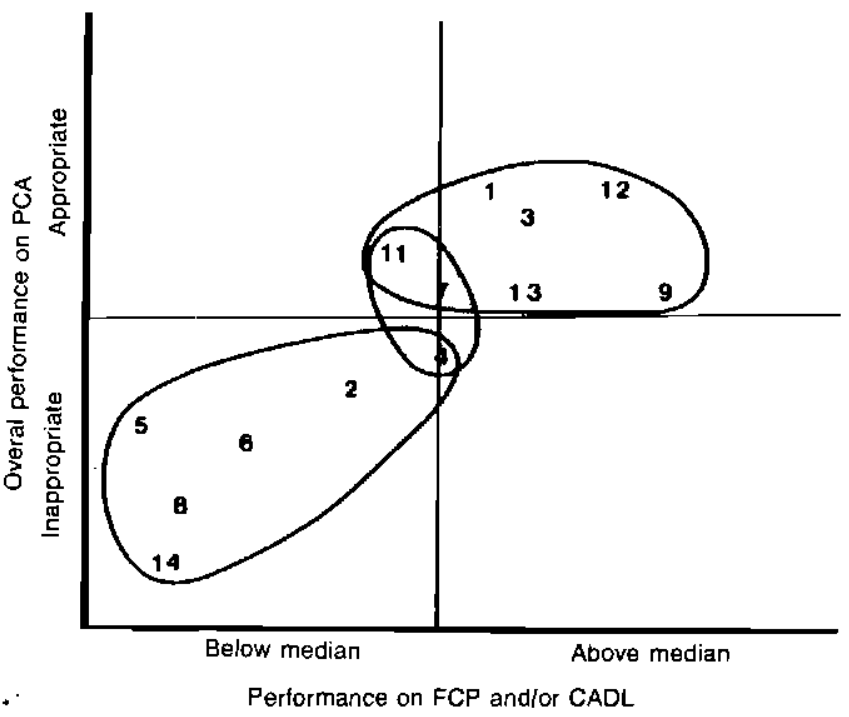

Figure 5 Comparison of Subjects' performance on PCA and other communication measures

Results thus suggest that the subjects showed differential retention of communicative skills as measured on the PCA - a finding sup- ported by Goldblum (1983) who applied Prutting's protocol to adult aphasics.

Further the results lend support to the idea that traditional methods of classification and assessment may need some reconsideration.

\section{POSSIBLE EXPLANATION FOR RESULTS}

Returning to the pragmatic framework presented in Figure 1, the results of the present study suggest that within a given communicative context (whose participants, channels, code, setting and context are at least partially specified) aphasic patients' rules for communicating differed from those of normals and between individual subjects. No striking evidence was observed however which suggested that such differences reflected the use of a completely distinct set of rules within any particular group. Rather, the patients' capabilities seem to lie on a continuum. Discourse, fluency, sociolinguistic sensitivity and non-verbal aspects were assessed in terms of communicative appropriateness. Results suggested that communicative competence is often well retained in aphasia and that difficulties pattern those of normals, occurring however with greater frequency. Davis (1983) has suggested that "Adult aphasia can be understood in part as a disturbance of normal processes". The effect of aphasia appears to be that of limiting or reducing the individual's capacity to apply the conversational maxims effectively. The maxims of quality and relation are properties of conversation concerned with basic truth conditions and semantic content. Control of such matters (particularly in scales A and B) was implicated in certain subjects. Quality and manner of production (reflected on Scales $C$ and $D$ ) are also affected by brain damage. The behaviours measured on Scales $\mathrm{E}$ and $\mathrm{F}$ might be seen as those strategies employed by the subject to overcome the communicative difficulties imposed by his defect.

The fact that there was a considerable degree of overlap between scales and between patients on the scales confirm that communication is after all a global process. The aphasic patient's control of communication and his adaptation to his difficulties reflects his overall communicative competence.

\section{UTILITY OF THE PCA}

With regard to the PCA, the results of the study have indicated in a preliminary sense the potential clinical utility of the profile as a measure to characterise aspects of aphasic language use. It appears to have fulfilled many of the criteria suggested by Crystal (1982) as being necessary properties of a linguistic profile:

- It will provide at a glance a simultaneous appraisal of the patient's areas of strength and weakness in a communicative sense.

- It may be used as a diagnostic or screening measure. For screening purposes only broad areas of communicative competence (e.g. Control of Semantic Content) need be characterised. For diagnostic purposes an in depth appraisal of specific aspects (e.g. topic management) could be explored.

- The PCA is flexible and by no means finite. It provides an opportunity to code 'Other' behaviours and also has a category for unanalysable features, (Could not Evaluate). Further the Conversational Unit may be varied according to the interest and the needs of the Examiner. It may be time- or turn-based. An additional flexible component of the PCA is that it can be used to characterize interaction between a patient and any interlocutor, not necessarily his therapist.

- Although unlike other linguistic profiles developed on children, it is not graded, it does appear to provide a basis for remedial intervention in that it has generated many hypotheses regarding the direction of future therapy for those patients examined . in the present study.

The Soush African Journal of Communication Disorders, Vol. 32, 1985 
Finally, al though the PCA emerged initially from the study of adult aphasic language, this certainly does not preclude its use with other language-impaired populations. Encouraging preliminary data has emerged from the application of the PCA to a group of head injured subjects (Irvine, 1984), a schizophrenic subject (Cohen, 1984) and some hearing impaired children (Sacks, 1984). Further ongoing research exploring the usefulness of the PCA in the area of leaming disability, dementia and in the clinical supervision of students is being explored by the author.

It is hoped that the next few years will see a burgeoning number of studies concerned with the refinement and broadened application of this apparently useful clinical tool.

\section{ACKNOWLEDGEMENTS}

The writer is indebted to Professor M.L. Aron, Head, Department of Speech Pathology and Audiology, University of the Witwatersrand for her valuable supervision of the research on which this paper was based. For financial assistance, the writer is indebted to the Human Sciences Research Council and to the Senate and Council Research Committees of the University of the Witwatersrand.

\section{REFERENCES}

Bates, E. Language in Context. New York, Academic Press, 1976. Bates, E. \& Johnston, J.R. Pragmatics in Normal and Deficient Child Language. Short course presented at ASHA Convention, 1977.

Behrmann, M. \& Penn, C. Non-Verbal Communication of Aphasic Patients. Brit. J. Dis. Comm. 19, 155-168, 1984.

Cohen, J. Weighted Kappa: Nominal scale agreement with provision for scaled disagreement or partial credit. Psychological Bulletin 70, 213-220, 1968.

Cohen, L. The Communicative Competence of a Paranoid Schizophrenic. Undergraduate Research Report. Dept. Speech Pathology \& Audiology, University of the Witwatersrand, 1984.

Crystal, D., Garman, M. \& Fletcher, P. The Grammatical Analysis of Language Disability. London, Edward Arnold, 1976.

Crystal; D. Profiling Linguistic Disability. London, Edward Arnóld, 1982.

Dálton, P. Hardcastle, W.J. Disorders of Fluency. London, Edward Arnold, 1977.
Davis, G.A. Aphasia and normal adult language processes. Paper presented at ASHA Convention, 1982.

Goldblum, G.M. Aphasia: A Societal and Clinical Appraisal of Pragmatic and Linguistic Behaviours. Unpublished M.A. Dissertation. Dept. Speech. University of California, Santa Barbara, 1984.

Goodglass, H. \& Kaplan, E. The Assessment of Aphasia and Related Disorders. Philadelphia, Lea \& Febiger, 1972.

Grice, H.P. Logic and Conversation. In P. Cole \& J.L. Morgan (Eds.) Syntax and Semantics. Speech Acts Vol. 3. New York, Academic press, 1975.

Halliday, M.A.K. \& Hasan, R. Cohesion in English. Hong Kong, Longman, 1976.

Holland, A.L. Communicative Abilities in Daily Living. Baltimore, University Park press, 1980.

Holland, A.L. Observing Functional Communication of Aphasic Adults. J. Speech Hear. Dis., 47, 50-56, 1982.

Irvine, L. The Communicative and Cognitive Deficits following Closed-Head Injury. Undergraduate Research Report, Dept. Speech Pathology \& Audiology, University of the Witwatersrand, 1984.

Keenan, E.O. \& Schieffelin, B.B. Topic as a Discourse Notion: A study of topic in the Conversations of Children and Adults. In C.N. Li(Ed.) Subject and Topic. New York, Academic Press, 1976.

Penn, C. Syntactic and Pragmatic Aspects of Aphasic Language. Unpublished Doctoral Thesis. University of the Witwatersrand, 1983.

Penn, C. Fluency and Aphasia: A Pragmatic Reconsideration. S. A. J. Comm. Dis., 30, 3-9, 1983.

Prutting, C.A. Pragmatics as Social Competence. J. Speech Hear Dis., 47, 123-134, 1982.

Prutting, C.A. The pragmatics of Language. S.A.J. Comm. Dis., 31, 3-5, 1984.

Prutting, C.A. \& Kirchner, D.M. Applied Pragmatics. In T.M. Gallagher \& C.A. Prutting (Eds.) Pragmatic Assessment and Intervention Issues in Language. San Diego, College Hill Press, 1983.

Sacks, J. Some Grammatical Discourse Features in the Older Hearing Impaired Child. Undergraduate Research Report. Dept. Speech Pathology \& Audiology, University of the Witwatersrand, 1984.

Sarno, M.T. The Functional Communication Profile. New York, Institute of Rehab. Medicine, 1975. 


\section{Medical \\ Software and Hardware Specialities}

- PRACTICE ACCOUNTING PACKAGES

- REHABILITATION AIDS

- PATIENT HISTORY MANAGEMENT

- COMPUTERS AND PERIPHERALS

- Also AVAILABLE •

- BUREAU FACILITIES

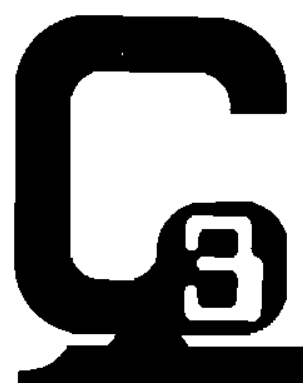

CLINICAL COMPUTER CONCEPTS

103 Highlands North Medical Centre,

cr. Louis Botha Avenue \& 3rd Avenue,

Highlands North 2192. South Africa.

PHONE (011) 440-9412

FOR EXPERT ADVICE 